MART IN NEIL BAILY

University of Maryland and McKinsey Global Institute

HANS GERSB ACH

Universities of Basel and Heidelberg and McKinsey Global Institute

\title{
Efficiency in Manufacturing and the Need for Global Competition
}

ON AVERAGE, manufacturing productivity (measured by real value added per hour) is higher in U.S. operations than in Japanese or European operations, but productivity by industry varies substantially from country to country. ' What is not well established is why such international productivity differences exist. This paper explores international productivity differences in manufacturing industries across Germany, Japan, and the United States and offers an explanation for them.

We develop an extension and a refinement of the industry-of-origin method to provide new measures of productivity in nine industries located in the three countries (automobiles, automotive parts, metalworking, steel, computers, consumer electronics, food, beer, and soap and detergent). Then we combine publicly available data with the industry knowledge and assessments by experts within McKinsey \& Company to determine the reasons for productivity differences. The nature of the explanation takes place at two levels, the first of which is at the production process level. We look for differences in the use of capital, technology, and skills-how the variables that enter the production

This paper is based on the McKinsey manufacturing project (McKinsey Global Institute 1993) and all data, unless otherwise indicated, is derived from that project. The project was directed by William Lewis, Heino Fassbender, and Martin Neil Baily. Hans Gersbach was the project coordinator. Other members of the team were Bart van Ark, Kathy Huang, Tom Jansen, Dirk Pilat, and Koji Sakate. Robert Solow, Francis Bator, and Ted Hall were advisors to the project. We have also benefited from comments by Peter Bernholz, Martin Hellwig, Gebhard Kirchgässner, and George Sheldon.

1. See, for example, Baily (1993). For other comparative studies, see Caves and others (1992), Jorgenson and Kuroda (1992), and van Ark and Pilat (1993). 
function differ across countries - and the synthesis of the industry results shows that physical capital and embodied technology are important factors that partially account for differences in labor productivity. The major part of the productivity differences, however, can be attributed to the way functions and tasks are organized and to the fact that some companies have designed the products they make so that they require less labor and material to manufacture.

Second, we take the explanation to a higher level. Why would managers choose to operate in different ways in different environments? How do managers change the production process? There have always been standard answers to these questions. For example, if factor prices are different or if the availability of proprietary technology varies, then managers respond with different production methods. We did not find these stock explanations to be satisfactory. First, relative factor prices in the three countries are not consistent with the direction of labor productivity gaps, and the observed differences in manufacturing design and in the way functions and tasks are organized do not seem to be driven by more detailed relative price comparisons. Second, when companies based in one country set up operations in another, they carry with them the production processes and productivity levels of their home country. That suggests that managers are not simply reacting to factor price differences. Third, when companies failed to use bestpractice technologies, it was not because these technologies were patented or secret in the industries we examined.

On this second level of explanation, we suggest that it is the nature of competition facing companies that strongly influences the productivity of the production processes used in a given industry in a given country and hence whether that industry is a leader or a follower or is becoming a leader. In particular, it is vital that industries in a given country compete against companies with the best manufacturing processes, wherever these leaders are located, so that they themselves become best-practice producers. Vigorous global competition against the best-practice companies not only spurs allocative efficiency, it can also force structural change in industries and encourage the adoption of more efficient product and process designs. Lively competition in a domestic or regional market is no longer sufficient. This conclusion represents a subtle departure from the more standard view of competition. 
As an illustration, consider the following two examples. First, in the 1980s German industry, on average, fell behind best-practice methods despite the competition it faced within Europe. During the 1960s and 1970 s, manufacturers in Germany raised productivity rapidly, achieving almost complete convergence with the United States in manufacturing productivity. But in the 1980s, German industries still concentrated on competition in Europe, where they had a significant productivity advantage, and did not compete against the emerging productivity leaders in Japan in the same way as U.S. companies did. For example, direct competition from leading Japanese producers caused the exposed U.S. automobile industry to respond with high productivity, while by 1990 the German industry-much more sheltered from Japanese competition-had done little to increase its productivity. Second, we observed marked productivity disparities within Japan. Those parts of Japanese manufacturing that competed in world markets had achieved best-practice methods or close to it. Those industries that competed domestically had relatively low productivity, even though the domestic industry could be quite competitive.

This study parallels the findings of the earlier McKinsey study on productivity in the service sector and adds to the validity of those results by finding a similar effect of competition on productivity in the manufacturing sector. ${ }^{2}$ Moreover, we were able to be more specific and detailed in describing how productivity differences arose at the production process level in manufacturing industries than we were able to in the study of services, and we could establish a quantitative link between the competitive intensity facing industries and their productivity performance. Obviously, an important and even larger follow-up question is why some industries remain isolated from exposure to best-practice methods; that issue, however, is beyond the scope of this paper. ${ }^{3}$

\section{Our Approach and the Results}

The starting point for calculating productivity levels across industries is the industry-of-origin approach. ${ }^{4}$ We measure productivity in terms

2. McKinsey Global Institute (1992) and Baily (1993).

3. For a discussion on this issue, see McKinsey Global Institute (1993).

4. See, for example, van Ark and Pilat (1993) and Pilat (1994). 
of value added per hour worked, which requires consistent input and output data and a way to convert value added from one currency into another. To solve the currency conversion problem, we calculate industry-specific exchange rates, denoted as industry purchasing power parities (industry PPPs). The industry PPP represents the number of units of a specific currency necessary to purchase an equivalent amount of industry's output. It therefore requires comparable products and their prices as they leave the factory gate for manufacturing companies in each of the three countries. The price of the standard item in deutsche marks in relation to the price in dollars yields a price ratio for the German-U.S. comparison. The industry PPP is then defined as a bilateral Fisher index, by calculating a weighted average of the individual price comparisons. (A similar calculation is made to determine the Japanese-U.S. comparison.)

Using the industry PPP approach on the level of four- or three-digit industries requires extensions and modifications in two different directions. ${ }^{5}$ First, making labor input and value added data comparable across countries required a series of adjustments to the data from the Census of Manufactures.

Furthermore, we modified the industry PPPs as they were calculated from data from the Census of Manufactures. Because the census data do not provide detailed price comparisons for industry PPPs, we used additional price comparisons and, in the case study of the food industry, we used the PPP from the International Comparison Project, adjusted for taxes and distribution margins, to calculate the industry-specific currency conversion. We focused on two main methods to obtain detailed comparisons of prices at the factory gate for products such as standard hot rolled sheet strips in the steel industry.

First, existing product category matches from the Census of Manufactures were adjusted for product mix and product quality differences. For example, in the automobile industry, the price relationship between the average car in Japan and that in the United States was adjusted for the mix of market segments. Moreover, differences in such things as reliability and performance of cars in the same market segment across countries were assessed by the price differential that an average con-

5. For details and discussions of the research protocol, see Gersbach and van Ark (1994). 
sumer with unrestricted access would be willing to pay. For instance, the quality adjustment for 1987 for the U.S.-Japanese comparison amounted to 12 percent in favor of Japanese cars. The German automotive industry enjoyed a 10 percent quality premium over U.S. cars in $1987 .{ }^{6}$ Similarly, German products in the metalworking industry commanded quality premiums over U.S. products in some market segments. The necessary adjustment for the whole metalworking industry was almost negligible, however.

Second, new industry PPPs were obtained from existing McKinsey studies or from surveys specifically carried out for this study. Note that in three cases industry PPPs had to be adjusted for price differentials of intermediate inputs because output and input price relationships differed. ${ }^{7}$

A sample of nine industries was selected that accounted for between 15 and 20 percent of employment and between 17 and 22 percent of value added of the manufacturing sector in the three countries. The industries studied were selected on the basis of the following criteria. First, we tried to cover as broad a range of the entire manufacturing sector as possible. Second, we wanted to include different types of manufacturing production methods, among them assembly and process industries. Third, we undertook case studies only where McKinsey and Company had sufficient knowledge to understand and determine the causality of productivity differences. Hence, although our case studies represent a broad variety of manufacturing industries, representation was not our only concern. Moreover, the food processing industry is much broader than the other industries and could be included only because the productivity differences in the industry as a whole and their explanations were representative of most of the subindustries.

We made specific calculations of average labor productivity, but that is not a complete measure of productivity. In the industries where capital productivity is important, we discuss capital intensity and its impact on labor productivity.

6. Unpublished data from McKinsey \& Company, Inc.

7. In calculating the industry PPPs, we focused on similar products that were likely to be exposed to international composition. The industry PPPs could thus be biased if interindustry price relationships are different across countries. In three industries (steel, automobiles, and consumer electronics), we were able to test for a potential bias; the bias was negligible. 
Table 1. Industry PPPs in 1990

(Bilateral Fisher Index)

\begin{tabular}{lcc}
\hline & \multicolumn{2}{c}{ Industry PPPs } \\
\cline { 2 - 3 } Case studies & Germany/U.S. & Japan/U.S. \\
\hline Autos & 2.24 & 114 \\
Auto parts & 2.24 & 120 \\
Metalworking & 2.18 & 138 \\
Steel & 1.9 & 170 \\
Computers & 2.06 & 154 \\
Consumer electronics & 2.97 & 115 \\
Soaps and detergents & 2.02 & 188 \\
Beer & 2.23 & 210 \\
Food & 2.06 & 241 \\
\hline
\end{tabular}

Source: Unpublished data from McKinsey \& Company, Inc.

To identify and explain the causes of observed productivity differences, we developed a simple framework, described later in this paper, that captures all major causes for differences in labor productivity and reflects their relationship to each other within a given hierarchy. To test and revise our hypotheses and assess the relative importance of the different causal factors, we analyzed publicly available data and made use of benchmarking studies by a team of McKinsey consultants and assessments of McKinsey industry experts. Our approach is certainly not standard from an economist's point of view. Moreover, because we rely on the aggregation of data from consultancy work, it is impossible to give a better description of the source in some tables and figures. We hope, however, that this approach reveals valuable insights for what has happened to productivity on a disaggregated level across countries, insights that are not obtainable by more standard approaches.

\section{Industry Results}

The industry PPPs that we used, shown in table 1 , cover 30 to 80 percent of the output in the nine industries. Table 1 reveals a wide variance among the industry PPPs. The industry PPPs for Germany are all above the average nominal exchange rate for 1990 of 1.62 deutsche marks per dollar, which reflects the common view that prices in Germany were higher than in the United States The Japanese industry PPPs are distributed around the 1990 exchange rate of 145 yen per dollar, with beer and food processing showing very high price levels, but with 
prices in autos, auto parts, metalworking, and consumer electronics being close to or below the exchange rate. This range is consistent with the strong international competitiveness of these latter industries in Japan.

Figure 1 shows a summary of the productivity comparisons for all nine of our industries, with value added per hour worked set at 100 for the United States. The German-U.S. comparisons show that labor productivity in 1990 was virtually identical for two industries (metalworking and steel). In the other seven industries, however, productivity in Germany is substantially lower than productivity in the United States. Figure 1 also shows that productivity in Japan is ahead of that in the United States in five of these industries; it is thus clear that German productivity is far behind the international productivity leader in several industries.

The U.S.-Japanese comparison shows strikingly wide variations in relative productivity. Food processing productivity in Japan is only a third of that in the United States, while Japan's labor productivity in steel manufacturing is more than 40 percent higher.

The three countries were at different points in the business cycle in 1990. The U.S. economy was weakening in 1989 and went into recession in 1990, while in Japan and Germany output was high in 1990. To address these differences, we examined capacity utilization data and labor adjustment over the business cycle. In three industries-autos, auto parts, and metalworking - the downward adjustment of Japanese productivity for differences in the business cycle relative to the United States was between 8 and 15 percent and therefore had a substantial impact on our results. The adjusted figures are reported in figure 1.

\section{Aggregate Results}

Our case studies covered a range of different types of industries, but we did not select an equal number of industries in each part of the manufacturing sector. For example, food processing in Japan employs more people than do steel, autos, auto parts, and metalworking combined. Moreover, because our case studies only cover roughly 20 percent of value added in the whole manufacturing sector in each country, our results are not a comprehensive test of the aggregate productivity results for manufacturing. Nevertheless, when we calculate the 

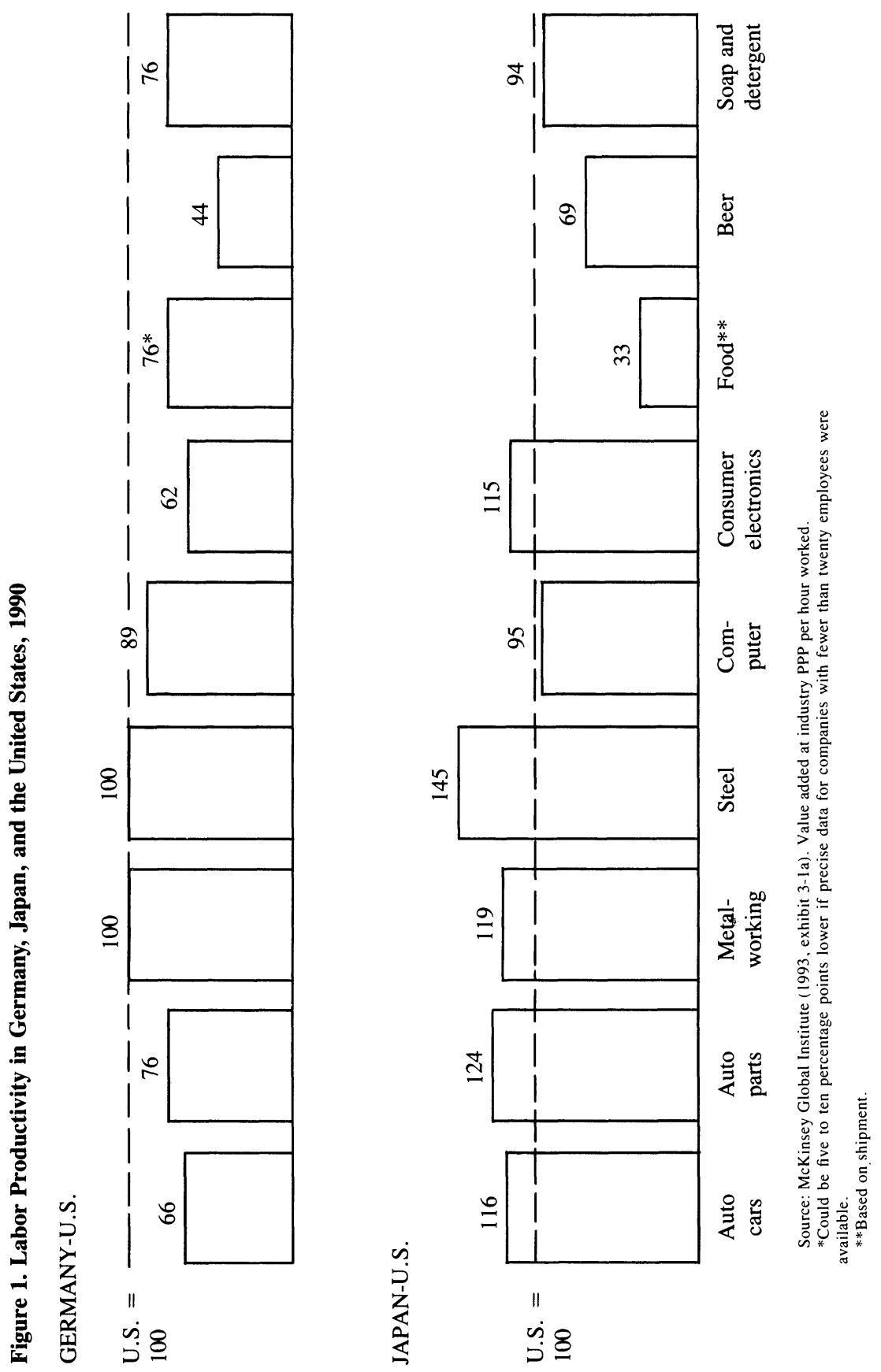
weighted average of our case studies, labor productivity was 83 percent of the U.S. level for Japan and 79 percent of the U.S. level for Germany. We used each industry's share of employment in the whole sample as the weighting factor. The weighting factors for Japan were automobiles, 6.9 percent; automotive parts, 19.6 percent; metalworking, 8.5 percent; steel, 6.9 percent; computers, 6 percent; consumer electronics, 10.3 percent; food, 41.1 percent; beer, 0.4 percent; and soap and detergents, 0.3 percent. Thus the food industry dominates the average productivity result. ${ }^{8}$

The average productivity results are roughly comparable to studies of aggregate manufacturing productivity ${ }^{9}$ even though we made changes in some of the original industry PPP's on the order of 30 to 40 percent. Our results confirm that, on average, productivity in Japan and Germany in 1990 was lower than in the United States.

\section{Productivity Differences and the Production Process}

On the first level of explanation, we look at proximate causes for productivity differences. What do operations in Germany, for example, do differently that makes output per hour worked higher or lower relative to their counterparts in Japan or the United States? Standard economic approaches based on decomposition techniques would call for some sort of growth or level accounting. We use a micro-oriented framework that starts like the accounting techniques with a production function basis, but that we then modified to include those determinants of productivity that detailed industry case studies found to be important.

To understand the rationale behind our approach, consider the following example. Two firms (or industries) in two countries produce exactly the same products as far as the buyer is concerned. The first firm, however, achieves higher labor productivity because its product design is easier to manufacture, which means it uses fewer materials and less labor. Furthermore, this firm requires labor skills that are different from those of the second firm. The more complex production process in the second firm might require precision metal-cutting skills that are not required by the simpler production process that the first firm

8. Unpublished data from McKinsey \& Company, Inc.

9. See, for example, van Ark and Pilat (1993). 
uses. In such a case, traditional decomposition techniques would make it difficult to determine the reasons for the productivity difference between the two firms (or industries). To do so, one would have to introduce a broad definition of "technology" and call all differences technology differences.

To develop the micro-level framework to better address the causes of productivity differences, we followed three steps. First, we developed a comprehensive list of factors that could explain productivity differences. Second, we ordered these factors by their inclusiveness, that is, a factor was considered to be more inclusive than another factor if a change in the first factor implied changes in a larger number of other factors than did a change in the second factor. ${ }^{10}$ Third, we attributed productivity differences to a factor if the differences are implied by this factor. In the example of the two firms given above, the design for manufacturing would emerge as the sole reason for the productivity differences because all other factor differences are an automatic consequence of the manufacturing design. Thus, whenever we single out important factors to explain productivity differences, these factors are viewed as causal factors.

By using these construction criteria, we generate a framework the components of which are not only exhaustive, but also mutually exclusive. Without this exclusivity, the sequential procedure would overestimate the total explanatory power of the factors. In the empirical work, not only is measurement a problem, but in some cases the factors are not decomposable at the level required. In such cases, those factors are combined into a new joint factor.

On the level of the production process, three basic elements explain possible differences in productivity. First, the estimates of labor productivity can differ if buyers perceive differences in output that cause them to value a product more highly than they value a similar product. We call this first basic element output. Second, differences in labor productivity can be caused by differences in the mix of basic inputs, such as capital goods, product design, labor skills, and raw materials and parts. We call this second element, the mix of production factors. The third element that can cause differences in labor productivity is the way the basic inputs are combined. We call this category operations.

10. In the empirical implementation, more inclusive factors should also be measured more accurately than other factors. 
These three basic factors can be decomposed further, depending on whether information to measure them is available. How much output a worker produces, on average, in an hour's work, depends on (1) the nature of the product, (2) the technology, plant, and equipment in use, (3) the scale of operations, (4) the ease with which the product is manufactured, (5) the parts, raw materials, and energy required, (6) the production workers' motivation and skill, and (7) the way the many tasks of production are organized.

Note that the term production factor is used somewhat looselyscale of operations is obviously not a production factor. Scale of operations, if it matters, is often linked to machinery and equipment in the form of achieving critical scale and therefore is not separable from machinery.

In evaluating the relative importance of these alternative factors, we considered them in sequence, starting from the top and working down. Hence, our framework may attribute productivity differences more to output mix and physical capital rather than to manufacturing design or organization of functions and tasks. We regarded this framework, however, as an opportunity to test whether "soft" factors such as manufacturing design and workplace organization are independent causes of productivity differences in industries across the countries studied.

Our framework can easily be related to neoclassical growth theory as set out by Solow or to the various versions of the new growth theory. ${ }^{11}$ The framework does differ from the standard production function analysis, however, by including elements such as product design and workplace organization and in the way productivity differences are attributed to the factors of the framework.

\section{Information Used to Assign Sources of Productivity Differences}

In determining the reasons for productivity differences at the production level, we used two different sources of information. First, publicly available data were used to assess the effect of product mix and physical capital on productivity. These data are taken either from the censuses of manufactures in the various countries or from capital stock estimates based on data gathered by the Organization for Eco-

11. Solow (1957). See also Romer (1986, 1990), Lucas (1988), and Grossman and Helpman (1991). 
nomic Cooperation and Development. No comparative capital data were available on the level of four-digit industries, so we started at the twoor three-digit level and then assigned capital to the component fourdigit industries on the basis of their shares of industry book values. Book values are highly suspect as measures of capital, but ratios of book values by industry can be used to estimate the shares of capital as long as the time paths of investment among the four-digit industries are similar. ${ }^{12}$

Second, we used the assessments of McKinsey's industry experts in conjunction with the results of extensive benchmarking studies. We also visited plants and conducted company interviews to fill remaining gaps. The benchmarking studies identified the manufacturing and managerial processes that are prevalent in each industry, selected facilities for comparison, observed and measured in detail how well these processes-and specific tasks within processes-are performed, and analyzed and interpreted the results according to our framework. Where possible, comparisons that amount to controlled experiments were used; that is, we were seeking to compare plants in an industry across countries that are similar in most dimensions but differ in one or two factors of our framework. For instance, suppose we want to examine the cause of the productivity difference between two plants that use similar machinery and equipment to produce the same products but that use different product designs and organize their workplaces differently. Then techniques such as reverse engineering and process analysis are used to estimate the amount by which labor and material inputs could be reduced if the products were redesigned so that the manufacturing design is comparable to best practice, but where the organization of functions and tasks remains unchanged except for those changes required by the change in manufacturing design. This procedure then allows an estimate of the partial effect of product design on productivity.

We turn now to a detailed discussion of each of the seven factors. Figure 2 provides a summary of the importance of each of the causal factors at the production level. Shaded circles indicate factors that are of high importance in explaining the productivity differences between the productivity leader and the industries in the other two countries.

12. For details, see Gersbach and van Ark (1994), van Ark and Pilat (1993), and Pilat (1994). 


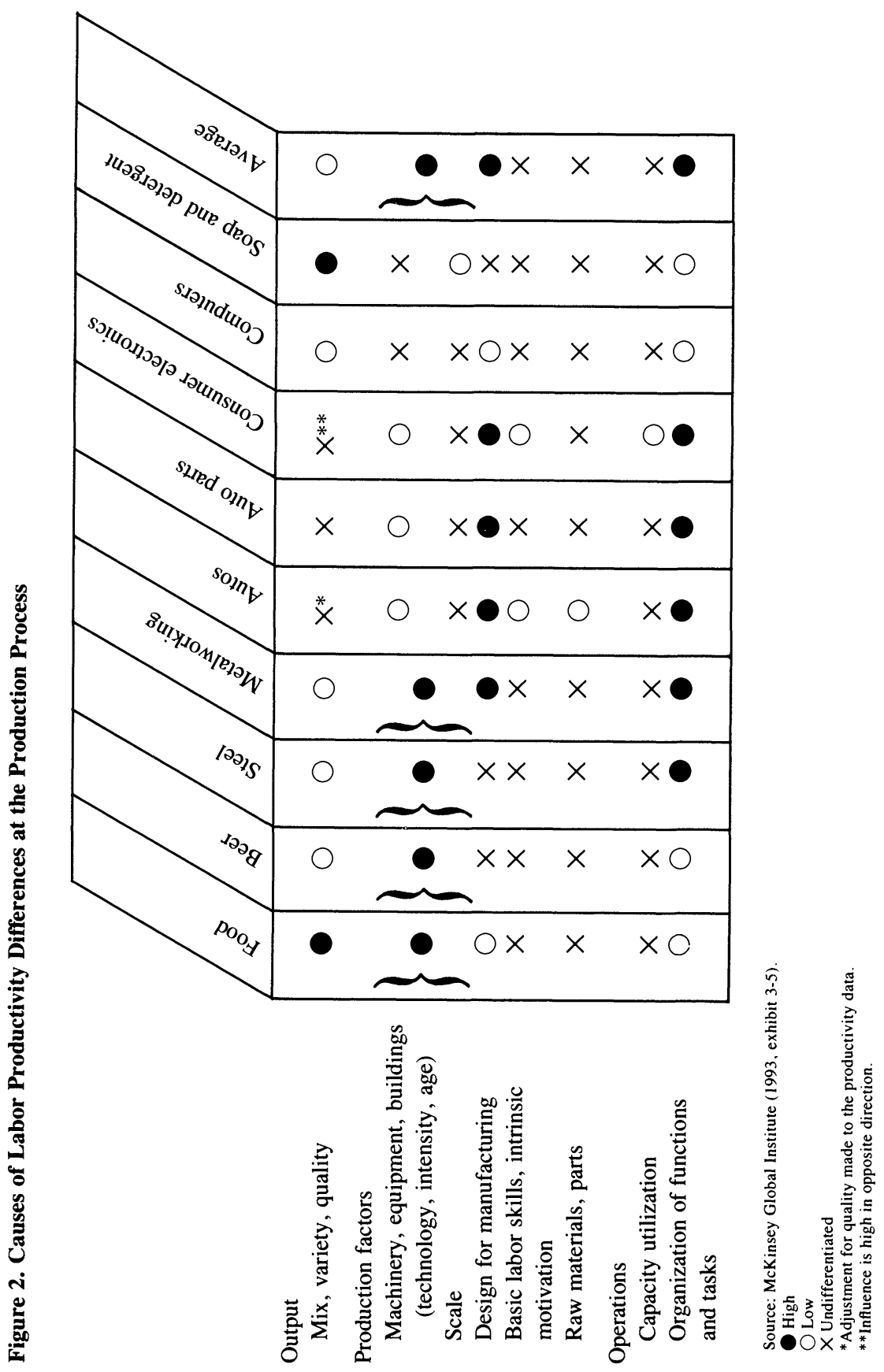


"High importance"' means that no other factor could explain significantly more of the productivity difference. Several factors may be rated as highly important if we cannot discriminate among them. Clear circles indicate this factor was of some importance in explaining productivity differences; the factor explains significantly less than a highly important factor, but its explanatory power for productivity differences is significantly greater than zero. An " $x$ " indicates that the factor was not an important differentiating factor. The "average" column summarizes the overall importance of each factor.

\section{Mix, Variety, and Quality Differences}

The results given in figure 1 were based on census data for the three countries, which provide information on the outputs and inputs of a group of plants that are defined to be in the same industry. Industries and products are not synonymous, however. For example, television sets and video cassette recorders (VCRs) are different products, but are both produced within the consumer electronics industry. The productivity results can, therefore, reflect the effect of differences in product mix, variety and quality. From the buyers' perspective, the same industries in two different countries never produce exactly the same output. Differences in output can influence labor productivity in three different ways:

OUTPUT MIX. Differences in the mix of products show up in finished products (liquid versus powdered detergents, for example), finished goods and parts (televisions versus electronic parts), and product life cycles (the mix of new and old products).

Within a given industry, some products have higher value added per hour worked than others, caused by differences in the use of inputs or simply by differences in the markups firms achieve in various industries. As a matter of simple arithmetic, the value added per hour for the industry is the average of the value added per hour for each product, with the products weighted by their share of the industry's total employment. If the mix of output for a particular industry differs from country to country, then overall value added per hour can differ, even if, viewed separately, the productivity for each good is exactly the same.

Thus, to measure the impact of output mix, we calculate value added 
Table 2. Effect of Product Mix and Variety on Labor Productivity in 1990

\begin{tabular}{lcc}
\hline Industry & Product mix & Product variety \\
\hline Steel & $5-10$ & - \\
Computers & less than 5 & - \\
Consumer electronics & $15-20$ & - \\
Soaps and detergents & $10-15$ & - \\
Beer & less than 5 & $5-10$ \\
Food & $10-15$ & $5-10$ \\
\hline
\end{tabular}

Source: Unpublished data from McKinsey \& Company, Inc. The entries represent the maximum that product mix or variety can explain in bilateral comparisons across Germany, Japan, and the United States. The effect is the change in percentage points of labor productivity if the mix and variety were assumed to equal that in the U.S. industry.

-Insignificant

per hour worked using U.S. employment shares for each country (table 2). The U.S. weights were chosen because all productivity results were based on bilateral comparisons with the United States.

In the soap and detergents industry, Germany suffers a significant productivity disadvantage because its share of powdered detergents is much higher than in other countries and making powdered detergents entails significantly lower productivity than making liquid detergent. If the German product mix was adjusted to match that in the United States, the German productivity figure would increase to 88 percent of the U.S. figure.

In consumer electronics, mix differences were also important, but they do not explain why productivity is so high in Japanese operations. The production of VCRs and audio equipment has lower value added per hour than the production of televisions, and Japan produces a larger share of VCRs and audio equipment than does the consumer electronics industry in either Germany or the United States. If the product mix were held level across all three countries, the productivity advantage for operations in Japan would be 16 percentage points greater than the industry average figure shown in figure 1.

In food processing, Japan has lower productivity, in part, because of its high share of output in product categories such as bread and seafood, which have a relatively low productivity in all countries.

OutPut QuALITY. Even if two industries produce essentially the same products, there may still be tangible differences, for which consumers are willing to pay and which require a different production process. Such differences are defined as price premiums an average consumer with unrestricted access is willing to pay for products that 
have the same purpose but that differ in their performance. Quality differences are based on the vertical product differentiation framework. Differences in consumer preferences across countries are obviously not treated as quality differences.

In the construction of the PPPs, quality differences, measured by quality premiums customers are willing to pay for products, have to be taken into account, and adjustments for these quality differences can have an important effect on measured productivity. Thus, provided the PPP has been correctly estimated, quality differences should not be a causal factor for productivity differences across countries. Any remaining differences attributable to product characteristics are captured under product mix.

Although our decision might be considered controversial, we assigned no quality advantage to German beer-not because there are no differences, but because experts determined that in most cases German beer could be brewed at optimal scale without reducing its quality or paying a significant productivity penalty. Hence, "quality" differences are not a result of the production process, but are driven by differences in customer preferences in conjunction with advertising. The latter aspects are not used to adjust productivity differences, but they can, of course, provide an explanation for productivity differences.

OUTPUT VARIETY. Plant-by-plant comparisons may reveal a different range of brands or products than company comparisons, even if the overall industry output mix is the same. Differences in the number or variety of products may cause differences in labor productivity because the production process is more or less complicated (greater variety may lead to more setup time, for example).

Product variety at the plant level was a source of productivity difference in two industries, beer and food, and in both cases it helped explain lower Japanese productivity. The proliferation of products in the food and beer industry in Japan hurts efficiency at the plant level, reducing productivity by reducing the lot sizes of production and delivery and increasing setup time. Although a plant usually achieves production of a greater variety of food products by using smaller and more flexible machinery and by reorganizing its workplace, the whole effect is captured under product variety according to the rules of our framework. 


\section{Physical Capital and Scale of Operations}

We define capital as machines, equipment, plant and buildings, and the hardware in information systems. Periodically, the physical capital and the embodied technology in an industry undergo a major transformation that results in large increases in productivity. When such a major transformation of capital takes place, it is often (but not always) connected to an increased scale of operations at the company, plant, or business function level.

Large variations existed across countries in the extent to which the industries we studied adopted new machinery and equipment including embodied technological change. A substantial fraction of output in one country may be manufactured using a process that has been largely superseded elsewhere. Because productivity varies with different generations of technology, the mix of generations of technology can be an important source of productivity differences across the countries. The main examples in our cases were food processors, breweries, steel production, and metalworking.

Food processors exploiting economies of scale dominate the industry in the United States, but account for only a small fraction of output in Japan. The average number of employees in operations in Japan is seventeen, compared to seventy in the United States. German output is produced to a large extent by multinational food companies, but a sizable craft industry remains in certain food categories. These differences in the scale and vintage of technology used in production account for much of the productivity difference across countries.

Large-scale breweries have taken over the beer industries in the United States and Japan, but beer production in Germany remains largely in small plants. The average production level in Germany is 11 million liters, compared to 352 million liters in the United States. In addition, U.S. plants have been able to take full advantage of high speed canning and bottling lines that require very large volumes to be economical. An efficient canning line operates at a rate of 2,000 cans a minute.

Steel minimill technology also represents a major new technology with much higher productivity. In this case, however, minimills operate on a much smaller scale than the integrated mills. Minimills proliferated 
first in the United States, but much of the equipment came from Germany. Minimills are now widely used in Japan too, but very little minimill production existed in Germany in 1990. The capital equipment in minimills is not the only causal factor in the steel industry, however; minimills also represent new ways to organize work in the steel industry.

In the metalworking industry, plants located in Japan have introduced methods for producing standard machine tools on industrial production lines with flexible manufacturing systems. In this case, two changes resulted in large productivity growth. More automated production was possible only because products were redesigned and standardized for easy manufacturing, allowing production of certain types of machines in substantially higher volumes. Machine tool makers in Germany have not adopted these innovations to the same extent.

Shifts to new generations of technology in our case studies were usually accompanied by large increases in capital intensity, as measured by the amount of capital per worker employed (or by the amount of capital per hour). These innovations actually reduced the ratio of capital to output, but they saved even more labor. For example, minimills in the steel industry require less capital per dollar of value added than integrated mills even though they operate with more capital per hour of work.

In figure 3 we show comparisons of the capital intensities for the four industries discussed above. To account for the time that the machinery is actually in operation, capital intensity is measured in gross capital stock per hours worked or per employee. The data on capital intensity in the steel, food, and beer industries support the hypothesis that the technology shifts described above for these industries usually involved a substantial increase in gross capital per hour or per employee. The main exception to this rule was metalworking: the industry in Germany was just as capital intensive as that in Japan, but few companies in Germany had linked machines into a production line, and so their productivity was lower as a result. ${ }^{13}$

Data on capital intensity can be deceptive when operations in one

13. Note that our capital intensity figures are for 1987 . The same picture for the four industries is also reflected in investment intensity from 1987 to 1990 . The one exception is the beer industry in Japan. It embarked on a massive investment campaign during this period, which moved its labor productivity slightly closer to the U.S. level. 
Figure 3. Capital Intensity

A. CAPITAl Stock Per hOUR WORKED, 1987

METALWORKING* STEEL BEER FOOD

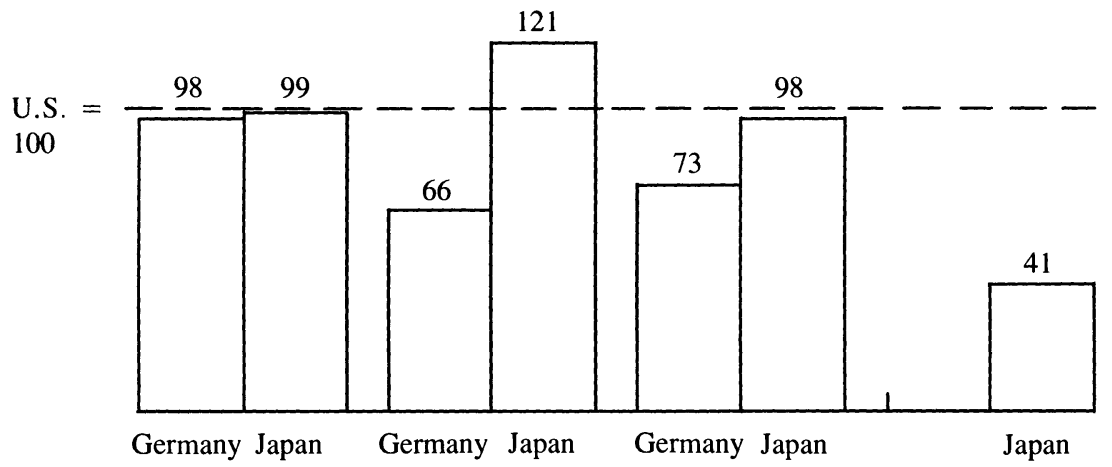

B. INVESTMENT PER HOUR WORKED 1987-1990, IN 1987 DOLLARS

METALWORKING** STEEL BEER FOOD

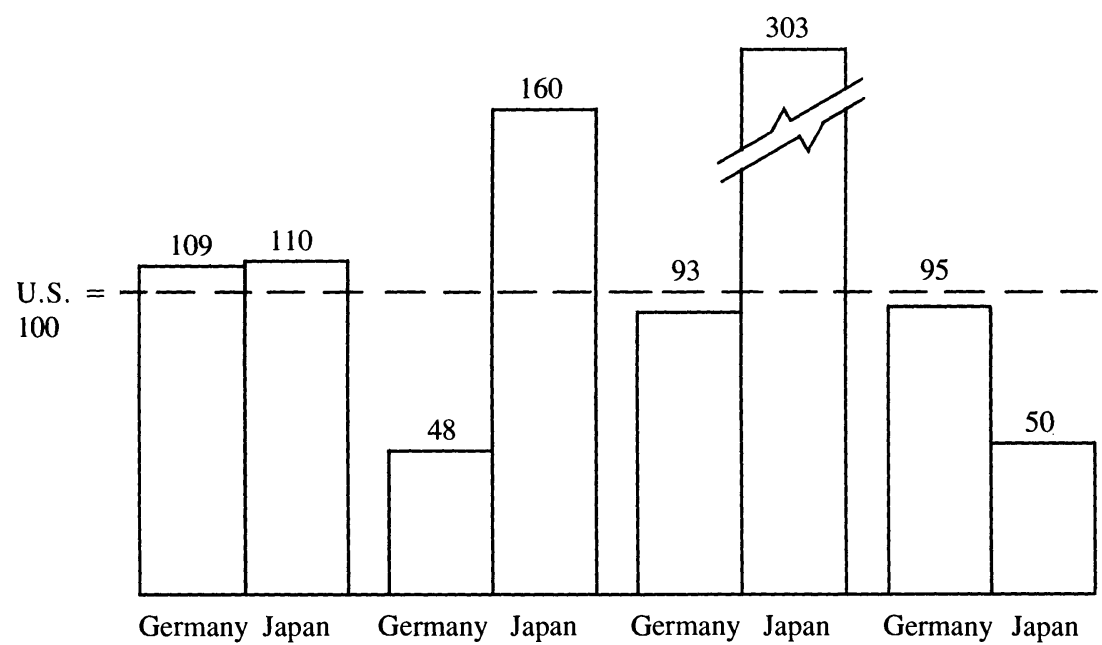

Source: McKinsey Global Institute (1993, exhibits 3-7 and 3-8), calculated from census data in the three countries. * Capital stock per employee.

**Investment per employee. 
country have an average labor efficiency that is very different from that in another country. For example, Japanese breweries were more modern and capital intensive in their design than breweries in the United States. Because of Japan's inefficient use of labor, however, the measured capital intensity is about the same in the two countries, and productivity in Japan is lower. Moreover, calculating the contribution of capital intensity differences to labor productivity using standard techniques (such as a constant return to scale technology) would misrepresent the impact of capital. Apart from the missing "quality" aspect in capital intensity data, we already noted that a new generation of capital often leads to a different scale of operations, and hence differences in capital also embody differences in efficient scale of operations.

Differences in the use of capital were not a major explanation for the productivity differences in other industries in our case studies. In autos, the U.S. companies invested heavily in capital equipment without matching the productivity level of the operations in Japan. The auto industry in Germany, however, was somewhat less automated than the United States and Japan, which explains in part the lower productivity in Germany. Japan's high productivity in auto parts was derived in part from adopting new production line methods, as in metalworking, which involved investment in automated equipment. Capital intensity was still lower in Japan than in the United States, however.

\section{Design for Manufacturing}

An important source of productivity advantages has been the ability to create product designs that are less complex, use fewer parts, and are easier to assemble, but that do not change the product from the customers' perspective. Manufacturing design describes techniques to increase the ease of fabrication and assembly. Techniques that are used to raise productivity through product design include standardizing components, optimizing the number of parts, and designing the product so that its manufacture can be automated and its assembly done with no or few tools. The industries in which design for manufacturing has been an important factor in explaining productivity differences are metalworking, autos, auto parts, and consumer electronics.

Although companies based in Japan have been the leaders in product 
design innovations, companies in the United States have been changing as a result of the transfer of the new methods. The Ford Taurus is one of the most successful early examples in the United States of a product designed for easy manufacture. Operations in Germany have been slow to adopt the innovations in manufacturing design. German-built cars, for example, require more parts and more complex assembly than cars designed in Japan. Benchmarking studies of the automotive industries in Germany and Japan, show that German disadvantages in manufacturing design account for roughly 30 percent of the productivity difference for plants that produced similar cars in 1990. We observed similar disadvantages in product design in both the consumer electronics and metalworking industries in Germany.

Moreover, in the consumer electronics industry, superior design for manufacturing results in significantly less rework and scrapping. Benchmarking studies revealed that manufacturing-oriented designs reduce labor inputs by as much as 17 percent.

\section{Basic Labor Skills and Intrinsic Motivation}

Productivity differences may also be caused by variations in the skills and the levels of motivation that production workers bring at the time they are hired. In the case studies, production workers usually account for 50 to 90 percent of the total work force. If employees in one industry in one country are more productive because of their basic education, they may be able to produce either more or better quality output in a given period of time within a given organization than employees elsewhere. Thus, the skill factor tries to capture differences in the quality of labor input, excluding factors influenced by management. This distinction is important because we count training that is carried out by the companies as an investment in improved production processes. Furthermore, differences in the skills of managers or engineers are included in our analysis under manufacturing design or workplace organization. Thus, we ask only whether the skills that production workers bring when they are hired are an important source of productivity differences, and there are three pieces of evidence to assess this.

First, companies that have achieved best-practice levels in one location have been able to replicate the same productivity advantages in 
their other plants around the world using workers of the transplant country. In seven out of the nine case studies, transplants that produce similar products are able to achieve similar productivity levels abroad.

Second, companies originating in countries with low productivity have also achieved best-practice productivity with their existing labor forces when they adopt new production processes. The clearest examples are the automotive companies in the United States, where the best plants of the big three auto companies had productivity that was comparable to all but the best Japanese plants.

Finally, general education levels and vocational education data usually show that the labor quality in Germany is at least equal to the U.S. level. ${ }^{14}$ General education levels in manufacturing are lower in Germany than in the United States, but this disadvantage is offset by vocational education through technical colleges and apprenticeships. Thus, it would be very difficult to argue that lower productivity in Germany, compared with that in the United States and Japan, is the result of lower basic skills of production workers in Germany. ${ }^{15}$

These three pieces of evidence indicate that labor skill and intrinsic motivation provide no major explanations for the cross-country productivity differences. The conclusion is subject to two qualifications. First, Japanese transplants with American workers show a small productivity disadvantage of 0 to 10 percent compared with Japanese home plants, because work force turnover is higher in the United States than in Japan, and that in turn requires more training. Moreover, some companies in Japan gain a small productivity advantage from higher levels of worker motivation. For example, some Japanese auto workers devote unpaid time to attend meetings about ways to achieve higher productivity and quality. This behavior results partly from incentives, such as quality circles, generated within the company and partly from intrinsic motivation.

14. See, for example, van Ark and Pilat (1993).

15. Note that the above evidence provides joint evidence that labor skill and intrinsic motivation are not causal factors with high importance. Here intrinsic motivation is defined as the cultural component of motivation, which does not depend on factors controlled by management. Stronger intrinsic motivation can result in less idle time, higher speed or quality of individual work, or more efforts to support colleagues. Motivational aspects attributable to the influence of managers are captured under organization of functions and tasks. 
In recent decades, the average years of education completed by the work forces in Germany and the United States have increased. In both countries, however, concern is mounting over the performance of the education system, the relative skills of the educated, and the lack of skills of the uneducated. In the United States, blue-collar workers are a declining percentage the total number of workers, and the wage premium associated with skill and education has increased sharply. ${ }^{16}$ Thus our conclusion about the lack of importance of basic skills is surprising and requires further comment.

Our measure refers only to the skills of production workers before they are hired. We did find that shifts to higher productivity production processes generally involve a significant increase in training and substantial efforts to heighten motivation. Furthermore, we evaluated only the skills of workers actually hired in these manufacturing industries, not those rejected. We have no information on the relative skills of the pools of workers not hired. Company recruiting shows, however, that the critical factors that drive hiring decisions are attitudinal factors that make production workers more flexible, less likely to call in sick, and more committed to remaining on the job for a long period of time. Academic test scores were not considered to be very important.

\section{Raw Materials, Parts, and Energy}

Labor productivity could be affected by special attributes associated with the raw materials, parts, or energy used as inputs. We did not find these attributes to be an important source of productivity differences. ${ }^{17}$

Differences in parts showed some small effects. The rarity of defects and the high quality of parts helps Japanese companies to minimize inspections of incoming parts and repairs and thus to achieve higher labor productivity. An important reason for assigning a small role to parts differences in explaining productivity differences is that we attributed the ease of fabrication and assembly to design for manufacturing.

16. See, for example, Freeman (1994).

17. Differences in raw material and energy prices across countries are accounted for in the measurement of productivity if value added is "double deflated," using a separate input deflator. This step was necesary in three case studies. 


\section{Organization of Functions and Tasks}

Plants that look similar otherwise and that produce similar products (after accounting for differences in design for manufacturing) still exhibit very large differences in productivity. These gaps result from the way in which work and communication are organized. No single large reorganization in any plant achieved higher productivity through this means. Rather, these plants have management structures that encourage continuous improvement using small- and medium-size changes. The organization of functions and tasks has emerged as a factor affecting relative productivity in all of our case studies. It is particularly important in steel, metalworking, autos, auto parts, and consumer electronics.

The organization of functions and tasks determines the effectiveness and efficiency with which inputs are brought together in the production process. This captures such matters as differences in the organizational structure and core processes of companies, which determine the division of labor and the way companies improve their organizations. It also captures differences in the way that companies organize internal communications and design incentive systems. Hence, the way industries organize their functions and tasks also affects the motivation of workers; different working environments and incentive schemes influence the willingness of employees to work efficiently.

Benchmarking studies reveal that more than half of the productivity differences between German and Japanese auto makers are attributable to differences in the way functions and tasks are organized.

Traditionally, technological systems have been differentiated by whether they are craft production or mass production. In mass production, special purpose machinery is substituted for labor to produce identical components, which are then brought together in a standardized assembly line. Craft production methods make extensive use of skilled labor to produce output that, in general, is much more customized. In recent years a third production system-which we call "agile manufacturing" - has begun to emerge. Agile manufacturing is based on more teamwork and flexible work rules; integration of workers' skills; low inventory; flat hierarchies and self-regulation; horizontal and vertical communications; delegation and quality and quantity objectives; flexible values for automation and integration of functions and tasks; both centralized and decentralized continuous improvements; more fre- 
quent product changes; and fewer, but more intense, relationships with suppliers.

These production differences do not apply in identical ways to all industries. And some elements of agile manufacturing were already used decades ago in mass production systems. The difference between agile manufacturing and traditional mass production can be seen most directly in the assembly industries, but they can also be seen to a degree in process industries. For instance, the relative high productivity of minimills, compared with integrated steel mills, is partly because the minimills have adopted lean or agile manufacturing elements. Moreover, the list of attributes under agile manufacturing does not suggest that more and more of these attributes are better. Changing cost and demand parameters can shift optimal levels in both directions. ${ }^{18}$

There is, of course, no one best way to organize production in all cases. For example, standard machine tools can be produced most successfully with some variant of agile manufacturing, but highly specialized machine tools requiring unusually high precision can be produced only by craft techniques. The adoption of a production system affects the competitive situation of the various industries. German machine tool makers have lower overall productivity than those in Japan in part because they have not adopted agile manufacturing for standard machine tools. For heavily customized machine tools, however, German tool makers have special skills and are often the sole world suppliers, which allows the German industry to sustain a strong export performance in this industry. In other market segments German products command a quality premium; however, these segments make up only a small portion of the whole industry and therefore do not show up significantly in the productivity data.

The tremendously efficient assembly processes developed in Japan were developed incrementally over many years, in large part by encouraging employees to propose and implement small steps of improvements. For this system to work, a flexible and responsive management system was required, and employees had to be assured that their proposed changes would not cost them their jobs. The rapid growth of output in Japan after World War II provided an ideal environment for

18. Because we focus on explaining existing productivity differences, we do not examine the underlying principles for agile manufacturing that have begun to develop during the last few years; see, for example, Milgrom and Roberts (1992). 
such a system. In today's era of slower output growth, there is an emerging tension in Japan between guaranteeing salaries and positions for employees and the need to undertake large restructuring in many industries.

Most of the traits of lean or agile manufacturing were epitomized in Toyota, which was around 40 percent more productive than any other automotive assembler in Japan in 1990. The so-called Toyota production system is predominantly a method of organization, not a proprietary technology. The inability of other companies to match fully the Toyota production system, but the ability of Toyota to replicate the production method within its operations overseas suggests that workplace organization can provide a source of competitive advantage because imitation is very difficult or costly.

Other Japanese companies and some U.S. and German companies have been able to adopt similar innovations and have achieved large increases in productivity. For example, the U.S. minimills are run with very lean methods; one firm with more than $\$ 1$ billion in sales operates with fewer than twenty employees in its headquarters, a much lower ratio than the integrated mills show. ${ }^{19}$

Not all industries in Japan score well on organization of functions and tasks. One example is the beer industry, where companies moved to modern brewing technology but kept their employees. Other examples of inefficiently organized functions and tasks in Japan are the food and soap and detergent industries, where inefficient distribution systems necessitate larger labor forces than are needed in the U.S. industries.

\section{Quantifying the Sources of Productivity Differences in Steel}

As an illustration, we put all of the findings together for the steel industry and made quantitative estimates of the relative importances of all of the different factors in our causality framework. The results are shown in figure 4 . There were some differences in the mix of products. Some specialty steels produced in Japan actually had slightly lower value added per hour than the average production in Germany or the United States. Product mix gave Japan a disadvantage of two to four percentage points. The greater adoption of minimills in Japan and the United States gave both countries a sixteen-point advantage over Ger-

19. Unpublished data from McKinsey \& Company, Inc. 
Figure 4. Causes of Labor Productivity Differences in Steelmaking, 1990

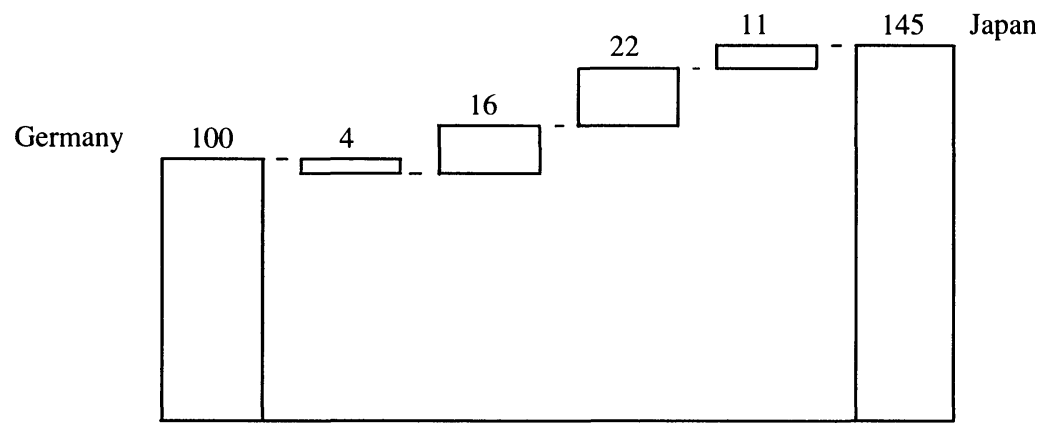

U.S.

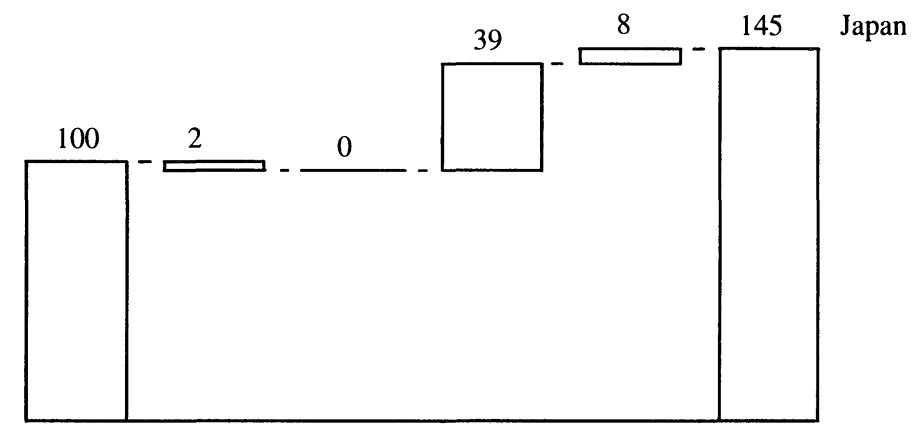

U.S.

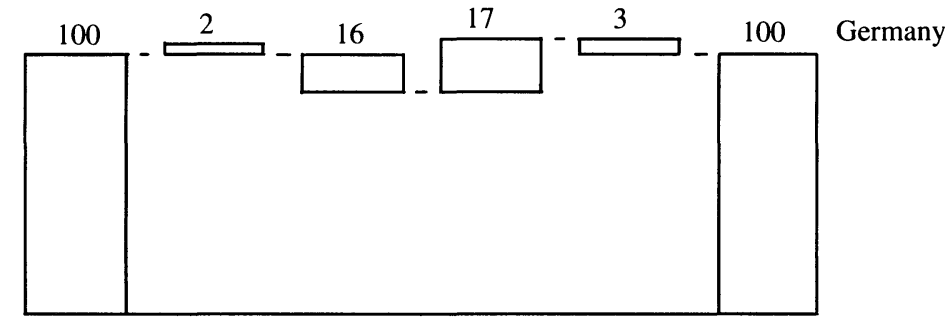

Productivity Product Minimill Technology/Operations Productivity mix share* equipment

Integrated mills

Source: McKinsey Global Institute (1993, exhibit D-9).

*Includes technology and operations. 
many. The integrated mills in Japan are much more modern than those in the United States and are run more efficiently, giving Japan a fortyseven point advantage over the United States. The German integrated mills are also more advanced than those in the United States. To some extent, the productivity advantage of Japanese operations comes at the expense of higher capital intensity. Total factor productivity was only 31 percent higher in Japan than in the United States in 1990. Moreover, because of overcapacity in Japan and further improvements in the other countries, the advantage in total factor productivity of Japanese operations deteriorated rapidly during the following years.

\section{Summary: Lessons for Productivity Analysis}

There is always a danger in drawing lessons from a relatively small set of industry case studies, but nevertheless some clear messages emerge from the results.

- Capital. In some industries, such as food processing and beer, shifting to a new generation of technology and higher productivity requires substantial new investment. But adding more capital to an existing business system was not always the means to higher productivity. For example, the push to much higher levels of automation in several U.S. plants in the auto industry did not pay off, whereas product and process redesign in Japan did.

- Scale and capital. Achieving optimal scale in operations (whether it be at the level of the company, plant, business function, or production line) allowed substantial productivity improvements and resulted in significant structural changes in several industries-food, beer, steel, and metalworking. These benefits of scale occurred in conjunction with new capital, however. In two industries (steel and metalworking), simultaneous innovations in design for manufacturing and organization of functions and tasks were necessary to reap the full benefits from scale and capital.

- Proprietary technology. There was little evidence that international productivity differences occurred because of differential access to proprietary technology. By the time a new product or service becomes a large part of the market, the technology to provide it using best-practice methods is available worldwide either through imitation or licensing. Examples include minimills 
and the technology to make mainframe computers ${ }^{20}$ It is possible, however, that our sample of industries and products has a selection bias regarding the significance of proprietary technologies.

- Manufacturing design and workplace organization. Innovations in manufacturing design that involve research and development and engineering turned out to be a significant differentiating factor. The case studies suggest that soft innovations to improve the organization of the production process can result in very large increases in productivity.

- Basic labor skills. Companies in all three countries were able to hire workers who could use best-practice methods.

These findings show how differences in production processes affect productivity. The next question, then, is why do production processes differ.

\section{Productivity Differences and the Nature of Competition}

As we examined the results of the nine case studies, a relationship emerged between the competitive environment in which industries operate and their productivity performance.

The material we use to assess this relationship is based more on subjective judgment than on hard fact. The purpose of the subjective component is to give an insider view and a broad perspective of the industries and to create hypotheses about the nature of competition. This is certainly a very different procedure from standard theoretical and empirical approaches, which focus on industry structure, the nature of competition among firms, and outcomes. ${ }^{21}$

To explore the ways in which competition has affected productivity in our case studies, we set up a three-way classification, depending upon whether the manufacturing operations in a given country are managed by companies that compete locally, regionally, or globally.

20. An interesting example is the beer industry. Much of the high-technology machinery used in breweries in the United States and Japan is made in Germany, but German breweries continue to use older, and less productive, craft technology.

21. Tirole (1988) and Scherer and Ross (1990). A more objective treatment of the relationship between globalization and productivity can be found in Gersbach (1994). 


\section{Local, Regional, and Global Competition}

Companies that compete locally are part of national industries in which small companies serve local markets. In some locally competitive industries, several small companies serve the same local market. In other cases, a single company is essentially the sole supplier to a local market.

Companies that compete regionally sell directly against the most productive companies in their own national or regional market but do not face the best external producers. Regionally competitive companies may export, but they do not export substantially to third markets where they have to compete against the best external producers. For companies that operate primarily in the United States, regional competition means that the companies are selling in the United States, Canada, or Mexico; in Germany it means that they are selling in Germany and the rest of Europe; and in Japan it means selling in Japan and the rest of Asia. An industry is regional if most of its production is managed by regionally competitive companies.

We classify companies as globally competitive if they compete in their own region and also against the best external producers. A globally competitive company may or may not be the productivity leader. The nature of the global competition can take several forms. Globally competitive companies can sell in their domestic market against transplant production or imports from the best external producers. These external producers must have a substantial market share. Globally competitive companies can export a substantial share of their production to the home market of the best external producers or they can set up transplants that compete directly against the best external producers. Globally competitive companies can compete against the best external producers, either through trade or transplants, in third countries. An industry is global if most plants are run by global companies.

The nature of competition according to our classification captures only which firms with which characteristics are competing with each other. Our classification is thus much less detailed than standard industrial organization notions of the nature of competition, which refer to dimensions such as price, quantity, product range, and product differentiation on which firms actually compete. ${ }^{22}$ Using the information from

22. Tirole (1988). 
the case studies, we made a subjective judgment and assigned each of the twenty-seven industries in our study (nine industries in each of three countries) to one of the three broad classifications. The assignments are described as follows.

In Japan the steel, metalworking, autos, auto parts, consumer electronics, detergent, and computer industries are operating under global competition. The beer industry is concentrated in a small number of firms and competes regionally. In the food industry, a consolidation process is just beginning with the growth of some national companies and the entry of multinational food processors. The bulk of the industry competes locally.

In Germany two of the nine industries compete intensively with world productivity leaders: computers and soap and detergents. The German computer industry is global, however, because the majority of operation in Germany are transplants from the United States, which is the productivity leader. Six German industries-processed food, steel, metalworking, autos, auto parts, and consumer electronics-are dominated by companies competing regionally in Europe. German automakers did not compete extensively in the main segments of the industry against Japanese producers until recently, and the auto parts suppliers were tied to the auto assemblers in Germany, with no large segment competing globally. Germany had the world's leading metalworking companies in earlier decades, but these companies rarely competed against Japan, the new productivity leader, in their European markets in the 1980s. The German beer industry is the only one of the nine industries that is local. Small breweries are either the sole local supplier or compete with other small local breweries.

In the United States, the processed food, auto, computer, soap and detergent, and consumer electronics industries all compete globally. The major domestic operations in food processing, consumer electronics, and soap and detergents belong to multinationals that have transplants in the leading world economies. The U.S. beer industry has thus far competed mainly in the North American market and is therefore classified as regional. Transportation costs make beer an uneconomical export except to serve niche markets. Transplants, until recently, have been uncommon in the industry. The bulk of output in the metalworking and steel industries in the United States is produced by companies that compete regionally; a few are global. The metalworking industry is in 
Figure 5. Differences in Labor Productivity and the Nature of Competition

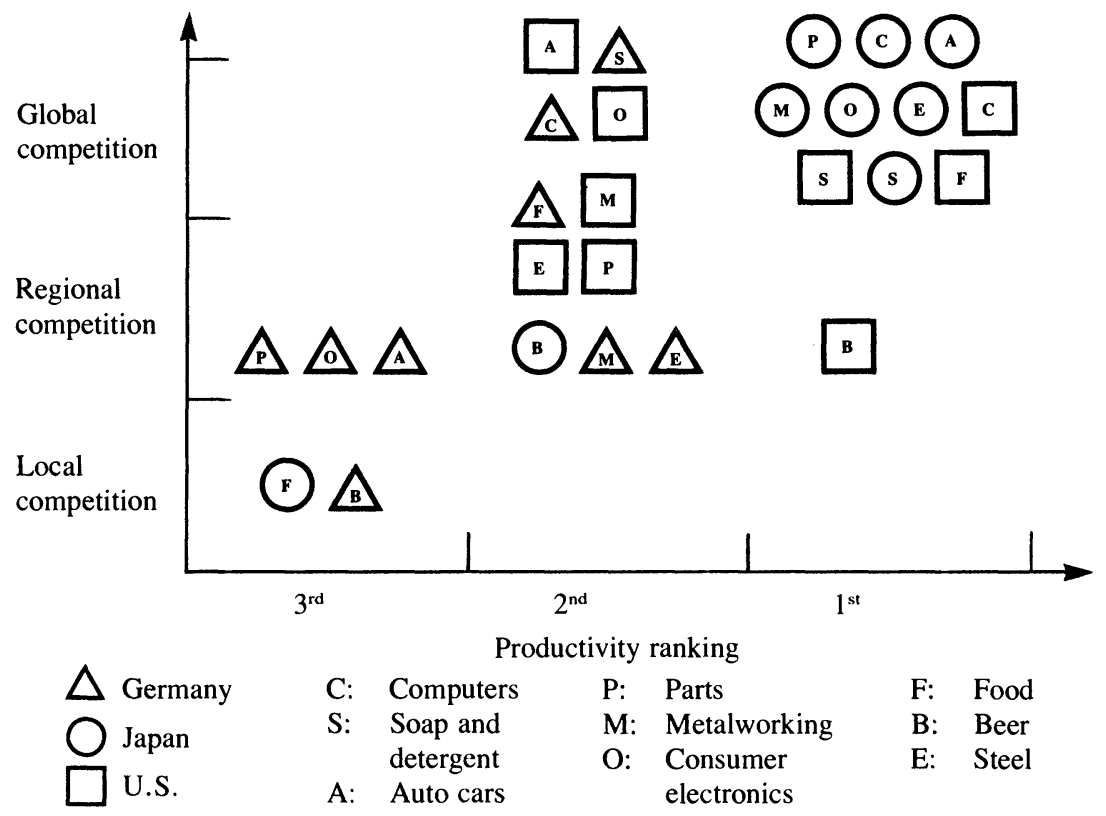

Source: McKinsey Global Institute (1993, exhibit 3-10).

transition: substantial production is performed by U.S. companies, but transplants managed by globally competitive companies headquartered in Japan also play an active role. The U.S. auto parts industry competes primarily in North America and hence is regional, as of 1990.

After classifying each industry, we then compared it to the productivity rankings for each industry in each country. The results, displayed in figure 5, show that this subjective assignment of range of competition was strongly associated with productivity.

A few cases deserve special mention. Germany has the lowest productivity among the three soap and detergent industries despite being globally competitive. The low productivity results not from weak competitive intensity, but from other factors such as its production of a proportionately larger share of powdered detergent. The local Japanese food industry and the local German beer industry are ranked third in productivity, as are several regionally competitive industries. In fact, their productivities (at 33 and 44 percent, respectively) are by far the lowest of this group. Local 
Figure 6. Changing Nature of Competition

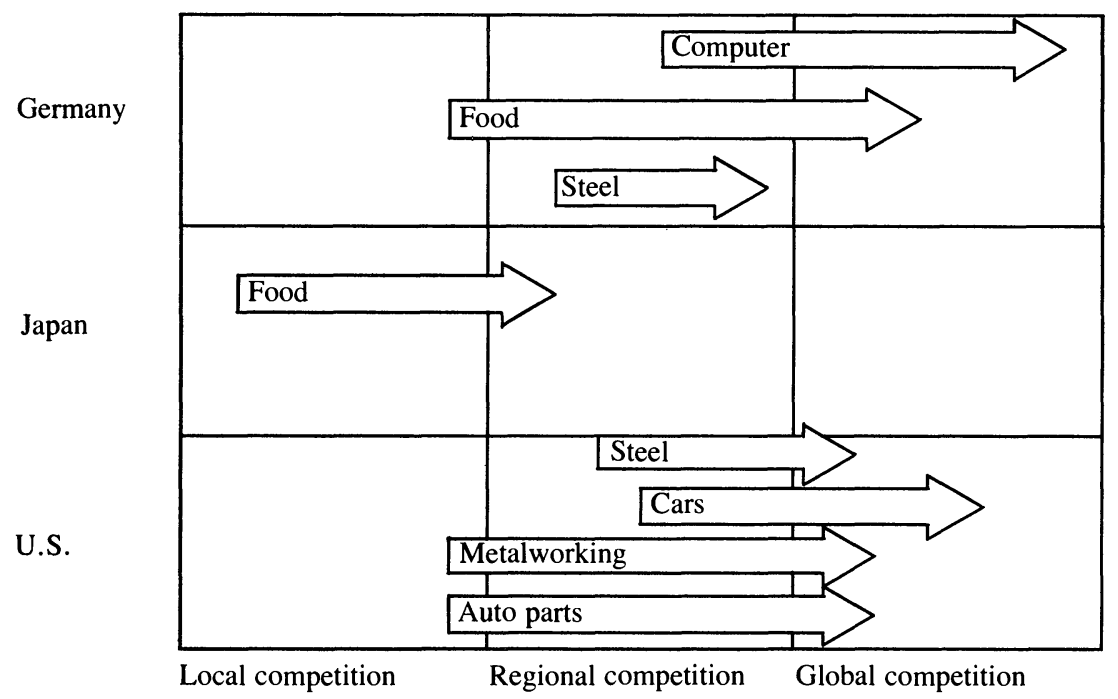

Source: McKinsey Global Institute (1993, exhibit 3-9).

competition with its associated lack of concentration and scale exacts a large productivity penalty. This penalty is not fully revealed by a simple productivity rank ordering within an industry.

In making these assignments, however, it is clear that an important dynamic component is still missing. Several industries are in transition as they adjust to changes in the environment, and thus our assignments represent an "average" at a particular point in time. An industry in transition may be largely global but may still have a regional component. Figure 6 gives our assessment from the case studies of where the main transition industries fall. Looking at these dynamic elements improved our ability to explain the productivity differences. For example, the U.S. auto industry is currently competing globally, but in 1990 it still had a substantial legacy of sub-par productivity operations left from its days as a regional competitor.

\section{Productivity Leaders and Followers}

To develop further the link between competition and productivity performance, we classified the twenty-seven industries as productivity 
leaders or productivity followers. The productivity leaders are the most productive manufacturing operations within the three countries. Five of the productivity leaders are based in Japan: metalworking, steel, autos, auto parts, and consumer electronics. The remaining four-computers, soap and detergents, beer, and food-are U.S.-based. The remaining eighteen industries are productivity followers; in all cases the productivity of their manufacturing operations is, on average, below that of the leader.

We then carried out two additional explorations. First, we used information from the cases to ask what factors combine to make an industry a productivity leader. Second, we asked whether there was a more objective link between the relative productivity of the follower industries and the extent of their competitive exposure to the bestpractice companies. We start by looking at the productivity leaders.

\section{Globalization among the Productivity Leaders}

With the exception of beer, all of the industry productivity leaders studied are exposed to both the best internal and external producers. All of the Japanese productivity leaders export large fractions of their output to sell in direct competition, primarily in the U.S. market, with the best external producers. Several Japanese companies in these industries have established transplants in the United States and Europe. The large computer companies originating in the United States have long exported around the world, set up transplants, and faced competition from imports. The companies that manage soap and detergent and food processing operations in the United States are multinationals, meeting competitors around the globe. The beer industry based in the United States is the only exception; it mainly competes regionally. German and Japanese breweries do not face greater global competition, however.

The United States has been the productivity leader in the computer, soap and detergent, food, and beer industries for some time. Japan, however, overtook its competitors within the last two decades to become the leader in the other five industries we studied. When the metalworking, auto, auto parts, and consumer electronics industries in Japan were followers, they were exporting and competing extensively with the productivity leader at that time. During this period, operations in 
Japan were well below the highest productivity operations worldwide, and imports and transplants were discouraged. This "protection" lasted well beyond the point where Japan's domestic operations could be described as infant industries. What initially moved Japanese domestic operations to compete abroad is an issue that is beyond the scope of this paper.

Followers improve their productivity by competing with and learning from the leaders. Our industries also show how revolutionary innovations helped industries to leap-frog the leaders. Agile manufacturing and design for manufacturing, which originated in auto operations in Japan, have proven to be enormously significant innovations. They use continuous incremental improvement, integrate product design engineering and process engineering, and utilize suggestions from line workers. These innovations have spread among the auto makers, to auto parts and metalworking (all major suppliers to autos), and have been adapted by other industries for their own production. Standardization and automation together with agile manufacturing and design for manufacturing were the primary factors that allowed the metalworking operations in Japan to overtake those in Germany and the United States.

We cannot say much more about gaining productivity leadership without going beyond our study. We do argue, however, that the intensity and scope of competition greatly affects the speed with which innovations are diffused and hence the size of the gap between follower industries and the productivity leaders that are observed across countries at any particular point.

\section{Productivity and the Globalization Index}

On the basis of our subjective approach, therefore, we have suggested that the nature of competition could well be a prime determinant of relative productivity levels. This result, however, is vulnerable to the criticism that we are seeing what we want to see. The assessment of the range of competition may be influenced by what we already know about productivity. To tackle the problem from a different angle, we restricted the globalization concept to productivity followers and constructed a quantitative index of globalization, which we then related to relative productivity.

The restricted concept of globalization is now defined as the exposure 
of a productivity follower industry in one country to the productivity leader wherever the latter's operations are located. ${ }^{23} \mathrm{We}$ apply the globalization definition to industries that are lagging in productivity. The globalization of productivity leaders will now be excluded because, in a circular way, they are trivially fully exposed to themselves. Note that the productivity results determine the sample of industries for whom we calculate the extent of globalization. Our definition of globalization can coincide with traditional approaches for characterizing globalization based on geographical considerations. It can also differ from a simple geographical definition. For instance, in the 1980s the German auto industry was exposed to the U.S. auto industry because companies headquartered in the United States owned a substantial share of the production facilities in Germany. The German industry, however, was less exposed to the productivity leader, Japan, than was the United States.

To derive the globalization of productivity followers, the following factors are taken into account.

- The exposure of transplants to the productivity leader through their ownership structure (for example, a U.S.-based auto transplant owned by a Japanese company is considered to be 100 percent exposed to Japan, the productivity leader in this industry).

- The exposure of the domestic operations of a productivity follower to transplants from the productivity leader or from other countries. (In the example above, the presence of the Japanese transplant affects U.S.-owned and -operated plants.)

- The exposure of the domestic operations of a productivity follower to competition with the productivity leader through trade: imports from the leading country, exports to the leading country, and exports to third countries where head-to-head competition with the productivity leader exists.

The calculation of the globalization index followed a three-step procedure. First, we split the production volume in a country and the trade flows into several parts, depending on their exposure. Second, we measured the exposure of each of these parts against the productivity leader using a construction principle that normalizes exposure to 100 percent if the domestic industry competes head-to-head with the leader. Third,

23. See Gersbach (1994) for more details. 
Table 3. Globalization of Domestic Industries in 1990

\begin{tabular}{lcl}
\hline Industry (productivity leaders) & Globalization & Country \\
\hline Auto (Japan) & 49 & Germany \\
Auto parts (Japan) & 43 & Germany \\
Metalworking (Japan) & 18 & Germany \\
Steel (Japan) & 2 & Germany \\
Consumer electronics (Japan) & 45 & Germany \\
Computers (U.S.) & 94 & Germany \\
Soap and detergent (U.S.) & 95 & Germany \\
Beer (U.S.) & 3 & Germany \\
Food (U.S.) & 43 & Germany \\
Computers (U.S.) & 81 & Japan \\
Soap and detergent (U.S.) & 78 & Japan \\
Beer (U.S.) & 3 & Japan \\
Food (U.S.) & 8 & Japan \\
Auto (Japan) & 73 & U.S. \\
Auto Parts (Japan) & 72 & U.S. \\
Metalworking (Japan) & 46 & U.S. \\
Steel (Japan) & 57 & U.S. \\
Consumer electronics (Japan) & 92 & U.S. \\
\hline
\end{tabular}

Source: Gersbach (1994).

an aggregation procedure led to the overall globalization index. The results of the globalization of the follower industries are given in table 3 , which shows large variations in the degree of globalization.

The extent of globalization can now be compared with the productivity differences of these industries. The results of a simple (heteroskedasticity consistent) estimate of the relation between relative productivity and globalization for the follower industries is shown in figure 7. The relationship is highly significant and the adjusted $R^{2}$ is surprisingly high given the cross-sectional data and the fact that the index gives only a relatively crude measure of the nature of competition in each market. ${ }^{24}$ The quantitative results provide support for the hypothesis that global competition enhances productivity.

One problem with the relation shown in figure 7, however, is that high productivity could be causing globalization rather than the other way around. The opposite causality would suggest that industries became highly productive first and then started to be exposed to the productivity leader. Obviously, exploring this relationship in depth

24. More sophisticated estimation techniques using the decomposition of the globalization index into its various components yields the same overall conclusion. 
Figure 7. Globalization vs. Relative Productivity

Relative productivity

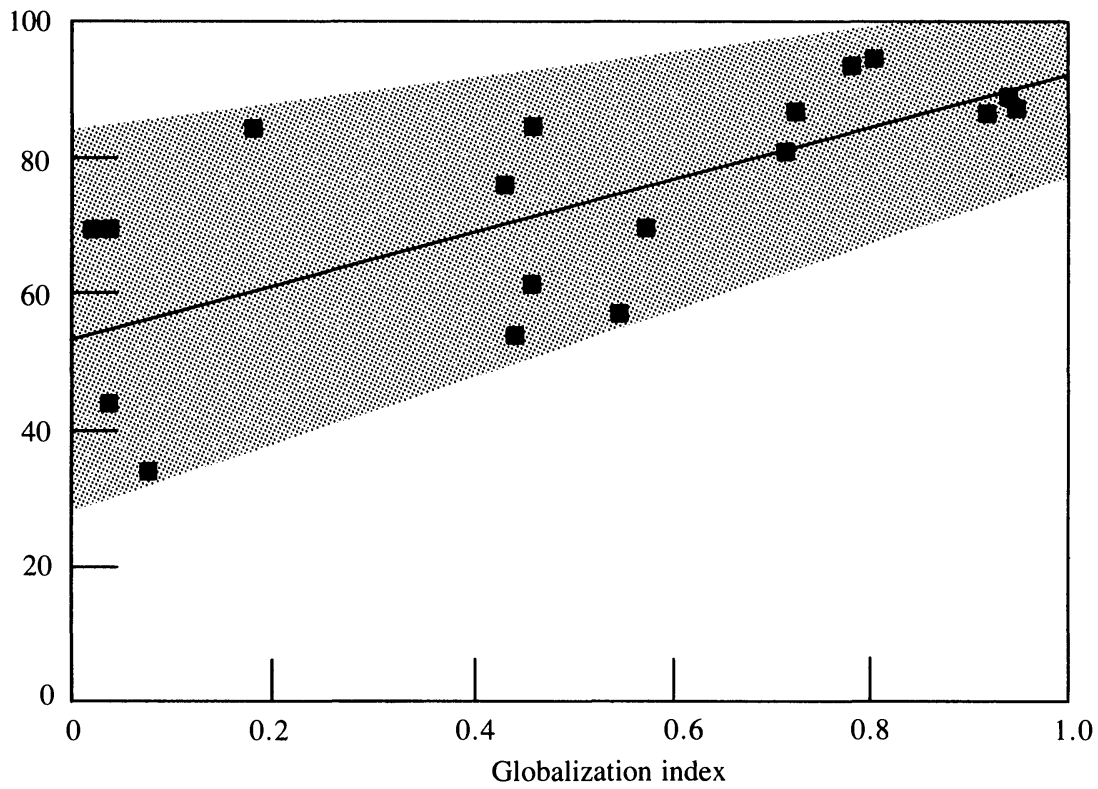

Source: McKinsey Global Institute (1993, exhibit 3-11), Gersbach (1994).

The squares represent the eighteen productivity followers in the case studies. Relative productivity is based on the productivity leader at 100 .

would require time series data and would be complicated by the fact that the extent of globalization depends on relative productivity levels. From a cross-sectional view, however, the reverse causality does not seem to fit the facts for the productivity followers in our industries. For instance, by far most of the globalization activities are driven by productivity leaders entering the market of laggards with trade and transplants. Industries that did not follow best-practice methods worldwide were forced to improve when they faced this competition from the productivity leader.

\section{The Need for Global Competition}

The theoretical literature is not clear-cut on the relation between domestic competition and productivity growth. For instance, the 
Schumpeterian view suggests that the prospect of future monopoly rents induces firms to innovate and that vigorous domestic competition can thus hurt growth when it facilitates imitation. More subtly, combining competition in research and development with ex post monopolistic rents is considered an appropriate way to create strong incentives for innovation. Standard theoretical arguments, however, often miss the simple role of competition in pushing firms to maximize profits by seeking innovations and changes in product design and workplace organization.

We go even further to argue that productivity is improved by competition and that it is improved most when the competition is global. Why is national or regional competition not enough to stimulate operations to achieve the highest productivity? The idea that trade, for example, can discipline domestic operations is a very old one. Our analysis, however, addresses the more subtle issue of why the entrance of a domestic firm into a product market can have very different implications for productivity than the entrance of a foreign company, either through foreign direct investments or trade. For instance, the transplants of Japanese auto companies in the United States have had a different impact on the productivity of the U.S. automakers than if the same factories had been built by the Big Three U.S. automakers or by a newly created U.S. car maker.

Increasing the geographic range of competition increases the opportunities for absorbing a new and more productive production process, especially if the range of competition includes best-practice companies. As long as U.S. auto companies, for example, did not compete against Japanese companies, they were unwilling to risk making radical changes in their production methods. Barriers to the adoption of bestpractice production methods can thus explain why regional competition is not enough to ensure best-practice productivity.

The second reason why international and domestic competition differ is the link between factor markets and product markets. Links among companies created by either the capital market or the labor market can reduce competitive intensity. Anecdotal evidence suggests that both effects were present in some of the industries we studied. ${ }^{25}$ It is obviously extremely difficult to disentangle capital market effects from

25. McKinsey Global Institute (1993). 
labor market effects. Nevertheless, the policy conclusion remains that global competition can ensure the speediest diffusion of best-practice production methods, which in our view will likely encourage the development of further productivity-enhancing innovations. ${ }^{26}$

\section{Conclusions}

This paper has drawn upon the expert knowledge and benchmarking studies of consultants working in manufacturing industries to determine why operations are more productive in one country than another. Traditional determinants, such as capital intensity and scale were found to play a role. But innovations such as design for manufacturing and workplace organization turned out to be even more important. Without drawing conclusions about overall labor force characteristics, we found that companies in all three countries were able to recruit workers with adequate skills. Training and motivating workers was important in achieving best practice. Although our study had no long-run focus (for example, research and development productivity and the evolution of product mix and varieties over time), innovations in design for manufacturing and agile manufacturing appear to be significantly more efficient ways to produce goods than is traditional mass production.

At the higher level of causality, we found a relation between the nature of competition and relative productivity levels. The greater the exposure of an industry to best-practice methods, the closer it is to best-practice productivity. We suggest the existence of a positive causal relation between global competition-that is, exposure to the best producers wherever their operations are located - and productivity. Domestic competition alone, however, is not enough to stimulate operations to achieve the highest productivity. This finding, if it is robust, implies significant gains from trade and direct foreign investment (transplants) over and above the traditional gains from comparative advantage. Trade and direct foreign investment force the adoption of best-practice production processes and facilitate the

26. Implicitly, our argument also suggests that the existing market for corporate control in the countries studied is only an incomplete substitute, if at all, for global product market competition. 
transfer of technology. Hence, the indirect effects of trade and foreign direct investment are significant, perhaps even more significant than the direct effects. From a policy viewpoint, the results of this study reinforce the idea that exposure to best-practice productivity methods promotes efficiency. 


\section{Comments and Discussion}

Comment by F. M. Scherer: The Baily-Gersbach paper distills findings from a McKinsey \& Company study of productivity differences in nine "industries", across three nations. (I enclose "industries" in quotation marks because some of the sample members, especially food, are defined more broadly than one might wish.)

Productivity comparisons are seldom better than the price indices used to deflate monetary output and input values. In this instance, real output estimates were based upon purchasing power parity indices for samples of identical products from each national industry. Here and on other aspects of the exercise-for example, in ensuring that products are really comparable, correcting for differences in vertical integration, and assessing differences in input quantities and qualities-problems could intrude. As the authors observe, many of the estimates required subjective judgments.

In preparing to discuss the paper, I reread the original, nearly booklength, McKinsey study upon which the paper is based. From my own research on several of the sampled industries, I found the detailed McKinsey discussion to be uncannily accurate. To be sure, some points raised doubts. On two of the most prominent examples, I checked with knowledgeable industry insiders and learned that my qualms were unfounded; the McKinsey assertions were correct. I am led to conclude that the study must be taken quite seriously and that the marriage of economists' methodological skills with a consulting firm's vast knowledge of industry detail can be a fruitful one.

The least persuasive part of the study is the comparison of aggregate 
productivity levels across industries. One's inference from a sample whose members vary greatly in size can depend upon how the sample components are weighted. The authors have used employment weights, and, as they recognize, this enhances the already disproportionate weight assigned to the broadly defined but relatively unproductive German and Japanese food sectors. A composite based upon deflated output values would be preferable, as would a finer but representative disaggregation of the food sector. From living in Germany for four years, I have reason to believe that at least some industries within the food sector there approach world-class labor productivity standards. I also find it hard to compare labor-intensive German (or French or Italian) bread - one of the great joys of European life-with the fluffy stuff that rolls off U.S. bakeries' automated production lines.

The paper's most important finding is that relative labor productivity tends to be highest in industries that are exposed through imports, exporting, and foreign direct investment to substantial competition from world-class producers. This parallels the conclusion of Michael Porter from an even more massive but less quantitative study that highlights the beneficial effects of squaring off with strong rivals. ${ }^{1}$ Although the evidence is persuasive, one would like to know much more about the chains of causation, especially the dynamics.

The authors' figure 6 shows that in recent years, several of the national industries have been in transition toward more thoroughgoing exposure to global competition. That analysis, I believe, covers too short a span of time to tell the whole story. If one had examined the situation as of 1960 , one would find that all of the U.S. industries except beer, auto parts, and steel were globally competitive. Most were also world productivity leaders at the time. Plainly, they lost ground in the ensuing decades. Most of the Japanese industries could hardly be considered globally competitive in 1960 . The main exception might have been consumer electronics. Transistorized radios from Japan dominated the U.S. market, but the big Japanese push in television sets was yet to begin (in 1962). ${ }^{2}$ There were inklings in 1960 of mounting Japanese steel competitiveness, but total steel imports then amounted to about 5 percent of U.S. demand, and of this, Japan originated about 
one-fifth, mostly at the low-quality end of the product spectrum (reinforcing bars, wire rod, nails, and so forth).

At the time too, most of the Japanese industries that later became world-class competitors were sheltered from competition at home by relatively high tariffs, obstacles to inward foreign direct investment, and "buy-at-home" preferences. Several of the Japanese industries covered by Baily and Gersbach were also shielded to some extent from competition by cartels. Steel, for example, had diverse price-fixing cartels and a rotation scheme orchestrated by the Ministry of International Trade and Industry (MITI) under which the leading firms took turns implementing capacity expansions. Domestic and export cartels among Japan's television manufacturers were the subject of a U.S. antitrust case that went all the way to the Supreme Court. ${ }^{3}$ And in 1971, the still-uncompetitive Japanese machine tool makers responded to " administrative guidance" from MITI to form a product specialization cartel aimed, among other things, at raising the share of units with numerical controls to 50 percent by 1980 . By 1977 Japanese machine tool exports to the United States surpassed those of Germany, until then the largest U.S. import source.

How then did the Japanese industries emerge from their protective cocoon to world competitiveness and productivity leadership? Plainly, the intense drive of Japanese industry to export-an orientation essential for their resource-poor nation to develop-contributed. So also, in the initial low-productivity stages, did low wages at prevailing exchange rates. From that start, virtuous circles ensued. Growth at home and abroad led to rapid investment; that investment embodied new technologies, at first licensed from abroad; rising investment induced domestic innovations in physical and managerial technology; implementation of those innovations led to improved competitiveness and more growth, and so on.

One must also explain why the leading firms in U.S. industries that were globally competitive in the 1960s let themselves be overtaken. One probable reason is that, having reached the summit in the world markets to which they had access, their growth slowed, which meant less new capital investment and hence less induced innovation and embodied new technology. Also, at least for steel, autos, machine tools,

3. Schwartzman (1993). 
and consumer electronics, competition abroad had not yet become enough of a threat to undermine creeping complacency with their dominant positions. It was only when imports into the U.S. market rose rapidly during the late 1970s and early 1980s (spurred in part by the high value of the dollar) that they experienced significant competitive shocks. Those shocks led makers of television sets and video recorders to turn "submissive," reducing their R\&D efforts and in effect ceding leadership to the challengers. ${ }^{4}$ But in autos and steel, the shocks precipitated positive behavioral changes that ultimately induced the rising global competitiveness illustrated in figure 6 .

Clearly, then, the gales of competition play an important role not only in causing resources to be allocated efficiently, but also in stimulating technological and managerial innovation and rooting out $\mathrm{X}$-inefficiency. I am less convinced than Baily and Gersbach that competition needs to be global to achieve this result. Testing the shock effects of increased imports into the U.S. market between 1972 and 1987, James MacDonald found that rising imports alone had a statistically insignificant impact on industries' measured labor productivity growth. ${ }^{5}$ But when interacted with four-firm seller concentration ratios, the import growth variables had positive and significant effects. Evidently, vigorous domestic competition prevented atomistically structured industries from accumulating organizational slack that could be shed under the pressure of rising imports. In the concentrated industries, however-of which autos, television sets, steel, detergents, and computers are examples-there was slack that could be reduced when import competition became fierce.

William Comanor and I studied the steel industry side-by-side with petroleum refining in an analysis of how antitrust case decisions of the 1910 s affected later performance. ${ }^{6}$ Standard Oil was broken into thirtyfour fragments; United States Steel Corporation survived a similar fragmentation suit. Standard's survivors evolved into world-class competitors; the steel industry stagnated under U.S. Steel's continuing price umbrella and found itself compelled repeatedly to seek protection from imports between 1968 and 1990. Only when the traditional steel pricing mechanisms were overwhelmed by excess capacity, import competi-

4. Scherer (1992).

5. MacDonald (1994).

6. Comanor and Scherer (Forthcoming). 
tion, and minimill competition during the 1980 s, did the industry take the productivity-raising steps needed to restore its international competitiveness. Comanor and I conclude that Sherman Act enforcement had long-run success in petroleum and failure in steel. Close parallels can be found for American Tobacco and DuPont, whose fragments thrived after early antitrust actions, and American Can and International Harvester, which survived Sherman Act actions but proved unable to meet growing competitive challenges.

Thus, I concur with the basic conclusion of Baily and Gersbach: vigorous competition spurs not only allocative efficiency, shrinking dead-weight loss triangles, but it also spurs X-efficiency, shrinking the much more important organizational slack and technological backwardness rectangles. More research is needed on the optimal mix of competitive challenges, that is, on when domestic competition is sufficient to achieve the desired result, and when global competition makes important incremental contributions.

Comment by Frank R. Lichtenberg: I would like to begin by commenting on the overall methodology used in this very interesting paper. The good news is that the analysis is based on an original and unique set of data, derived from benchmarking studies and company interviews. The bad news is that, because of the confidentiality of the data (and the extremely high cost of acquiring this information), replicating this study (in order to validate its conclusions) seems virtually impossible. The difficulty of replicating the analysis is far more severe even than with confidential Census Bureau data; in principle, at least, another investigator can go to the Census Bureau and check the calculations. With this paper, it may very well be that the authors' conclusions are right, but verifying what they have found would be extremely difficult; that makes me a little bit uncomfortable.

The authors begin by considering cross-country differences in labor productivity in a variety of industries and asking whether these differences are attributable to the "usual suspects" in neoclassical analysis: physical capital, human capital, and technology, for example. They find, to their surprise, that human capital (skills) do not seem to account for the differences, nor does most formal research and development or access to technology.

The fact that skill differences are not an important source of produc- 
tivity differences is somewhat surprising to me, because a number of recent theoretical and empirical papers have suggested that the returns to (or productivity impact of) skill may be quite large. In particular, Michael Kremer's "O-Ring theory" of production, which is predicated on notions of skill complementarity and teamwork (if one person makes a mistake, the entire team's output is destroyed), implies that small differences in average skill levels would yield very large differences in productivity. ${ }^{1}$

So, Baily and Gersbach may be quite right that skills do not vary much across these three countries, but if, as these other papers suggest, the returns to skill are very high, human capital per worker would not have to vary much, to cause large productivity differences.

Also in connection with the skills issue, the authors argue that "intrinsic motivation" is not a differentiating factor. I think that this argument is based on pretty tenuous evidence, however; the only objective indicator of "intrinsic motivation" they refer to is the fact that some Japanese workers go to meetings that they are not required to attend.

Baily and Gersbach argue that the important factors contributing to observed differences in international productivity levels are what they call "soft innovations" in design, manufacture, and organization of the work force. They then proceed to ask why the Japanese have exhibited a greater propensity to develop and implement these soft innovations than the Americans and the Germans.

The key hypothesis of the paper is that these differences are mainly attributable to differences in the extent and nature of (product-market) competition in different industries and countries. In a nutshell, their main hypothesis is: Competition is good for efficiency. They also offer this secondary hypothesis: Foreign competition is even better than domestic competition for productivity.

These hypotheses seem to be about efficiency or productivity levels, which is what the authors actually examine in the paper, not about growth rates. But some of their discussion seems equally, if not more, applicable to growth rates. They say, for example, that the leading industries are those that adopt continuous improvements and that the intensity and scope of competition may speed the diffusion of innova-

\section{Kremer (1993).}


tion. The empirical analysis does not address productivity dynamics, although Baily and his coauthor have done so in previous research.

Considerable work has been done on the relationship between competition - in particular, openness - and productivity. I think the authors could do a better job of relating their work to this literature, most of which has really been about productivity growth. Harrison has recently prepared a review of this literature. Her main findings are that there is a positive correlation between openness and growth, but there are serious questions about causality. In fact, simple Granger-causality tests performed by Harrison on cross-country data suggest that the causality runs in both directions: openness causes growth but growth also causes openness. $^{2}$

The authors find a positive correlation between globalization and efficiency (see their figure 7). But the causal structure underlying that correlation is somewhat ambiguous. I will use a couple of athletic analogies to illustrate this ambiguity. It is probably true that, if you want to be a good tennis player (or improve your tennis), you should play against people who are better than you. This is the argument that the authors are making. It is also true that kids playing in national soccer championships are likely to be better than kids playing in the local soccer league, but this is primarily an artifact of the selection mechanism: to be nationally or globally competitive, you first have to be a very strong player.

The issue of potential simultaneity in the relationship between globalization and efficiency is by no means unique to this paper. Bernard and Jensen's finding that plants that export are more efficient than those that do not poses a similar problem of interpretation.

As to the relative efficacy of foreign and domestic competition, Baily and Gersbach offer two reasons why they expect foreign competition to be more effective. The first is simply that if you are faced with the world's best, you are sampling from a larger distribution of potential practices, and the highest order statistic from that distribution is likely to be a better draw than one from just a local subset of that distribution. That makes sense to me. A second reason is that in domestic competition, firms have contact with one another in input (capital and labor) markets as well as in the product market, whereas that is not the case

2. Harrison (Forthcoming). 
in international competition. I am not convinced of this. Indeed, I have the impression that the capital market is now reasonably global in scope: Toyota and GM are, in a sense, competing in the same capital market, even though they are in different countries.

Baily and Gersbach seem to suggest that vigorous product market competition is almost a necessary condition for high efficiency, but substantial evidence suggests that a competitive capital market (or market for corporate control) can sometimes serve as a pretty good (albeit not perfect) substitute. Even when the firm's managers are not disciplined by rival producers, the threat of a takeover may prevent them from squandering the firm's resources and pursuing inefficient policies. Baily and Gersbach cite as an example of lean operations a U.S. minimill that had fewer than twenty employees in headquarters; I have shown that takeovers and leveraged buyouts often reduce corporate overhead in the same kind of way. ${ }^{3}$

General Discussion: Several participants were concerned about the confidentiality of the study's data and the ability of other researchers to replicate the paper's results. Karl Scholz argued that the authors' findings can be checked by examining data on relative wage differentials across countries in the industries on which the paper focused. Such data, if they were to prove consistent with the pattern of productivity differences reported by the authors, would provide additional support for their conclusions. Zvi Griliches said that, as long as the authors have made their research protocols clear, other economists should have no problem in performing similar studies. Nevertheless, he acknowledged that such studies might be somewhat costly. Griliches went on to suggest that, in general, researchers are far too willing simply to wait for economic data to be dumped in their laps by, for example, the Census Bureau. He argued that it is often necessary to go out and gather new data to gain crucial knowledge about important economic issues and commended the McKinsey group for their efforts in this area.

Timothy Bresnahan felt that the long-run impact of globalization on productivity practices still remains unclear. He argued that global competition might not lead to the continual adoption of new and better practices and, concomitantly, a permanent increase in the rate of tech-

3. Lichtenberg (1992). 
nical progress; instead, it might only yield one-time opportunities for firms to exploit the best existing organizational methods.

Ariel Pakes encouraged the authors to provide more information on the issue of causality. He argued that it is difficult to determine whether globalization causes a firm's productivity to increase or, conversely, whether a firm's high productivity enables it to become global. Pakes also suggested that the authors look at the effects of exogenous events on globalization. Along these lines, he noted that Japan's successful penetration of the U.S. auto market began when the oil price shock of 1973 increased the demand for small cars, which, at that time, were produced primarily by Japanese firms. This Japanese competition was, of course, the primary force ultimately responsible for bringing about the globalization of domestic American automakers. Finally, Pakes suggested that the authors provide more information on relative growth and capital vintage in the subsectors of the industries examined in the paper. He said that these factors could strongly affect the results in an industry such as steel, where striking changes in technology occurred during the period covered by the authors' data.

Peter Reiss asserted that perhaps only one-fourth of research and development is aimed at process enhancements, while the remaining three-fourths are directed toward product improvements. According to the authors' logic, he argued, globalization should lead to product differentiation and, ultimately, competition over product characteristics. Because the authors have calculated their purchasing power parities using homogeneous products, differences in productivity that are driven by product differentiation and quality are not likely to be captured in the paper's results, he said. 


\section{References}

$\rightarrow$ Baily, Martin Neil. 1993. "Competition, Regulation, and Efficiency in Service Industries." Brookings Papers on Economic Activity: Microeconomics 2: 71-159.

Caves, Richard E., and others (eds.) 1992. Industrial Efficiency in Six Nations. MIT Press.

Comanor, William S., and F. M. Scherer. Forthcoming. "Rewriting History: The Early Sherman Act Monopolization Cases." Journal of Business Economics.

Freeman, Richard B., ed. 1994. Working under Different Rules. New York: Russell Sage Foundation.

Gersbach, Hans. 1994. “Does and How Does Globalization Matter?” University of Basel.

Gersbach, Hans, and Bart van Ark. 1994. "Research Memorandum: Microfoundations of International Productivity Comparisons." Institute of Economic Research, University of Groningen.

Grossman, Gene M., and Elhanan Helpman. 1991. Innovation and Growth in the Global Economy. MIT Press.

Harrison, Ann. Forthcoming. "Openness and Growth: A Time-Series, CrossCountry Analysis for Developing Countries." Journal of Development Economics.

Jorgenson, Dale W., and Masohiro Kuroda. 1992. "Productivity and International Competitiveness in Japan and the United States, 1960-1985." Economics Studies Quarterly 43 (December): 313-25.

$\rightarrow$ Kremer, Michael. 1993. "The O-Ring Theory of Economic Development." Quarterly Journal of Economics 108 (August): 551-76.

Lichtenberg, Frank R. 1992. Corporate Takeovers and Productivity. MIT Press.

$\rightarrow$ Lucas, Robert E. 1988. "On the Mechanics of Economic Development." Journal of Monetary Economics 22 (July): 3-42.

$\rightarrow$ MacDonald, James M. 1994. "Does Import Competition Force Efficient Production?' Review of Economics and Statistics 76 (November): 721-27.

Maddison, Angus. 1991. Dynamic Forces in Capitalist Development: A LongRun Comparative View. Oxford University Press.

McKinsey Global Institute. 1992. Service Sector Productivity. Washington, D.C.: McKinsey \& Company, Inc.

- 1993. Manufacturing Productivity. Washington, D.C.: McKinsey \& Company, Inc.

Milgrom, Paul, and John Roberts. 1992. Economics, Organization and Management. Prentice-Hall. 
Pilat, Dirk. 1994. The Economics of Rapid Growth: The Experience of Japan and Korea. Brookfield, Ver.: E. Elgar.

Porter, Michael E. 1990. The Competitive Advantage of Nations. Free Press.

$\rightarrow$ Romer, Paul M. 1986. "Increasing Returns and Long-Run Growth.' Journal of Political Economy 94: 1002-37.

$\longrightarrow \rightarrow$ 1990. "Capital, Labor, and Productivity." Brookings Papers on Economic Activity: Microeconomics 337-67.

Scherer, F. M. 1992. International High-Technology Competition. Harvard University Press.

Scherer, F. M., and David Ross. 1990. Industrial Market Structure and Economic Performance. $3 \mathrm{~d}$ ed. Houghton Mifflin.

Schwartzman, David. 1993. The Japanese Television Cartel: A Study Based on Matsushita v. Zenith. University of Michigan Press.

$\rightarrow$ Solow, Robert M. 1957. "Technical Change and the Aggregate Production Function.' Review of Economics and Statistics 39 (August): 312-20.

Tirole, Jean. 1988. Theory of Industrial Organization. MIT Press.

$\rightarrow$ Van Ark, Bart, and Dirk Pilat. 1993. "Productivity Levels in Germany, Japan, and the United States: Differences and Causes." Brookings Papers on Economic Activity: Microeconomics 2: 1-69. 